\title{
Protective role of antioxidant vitamin $E$ and catechin on idarubicin-induced cardiotoxicity in rats
}

S. Kalender ${ }^{1}$, Y. Kalender ${ }^{2}$, A. Ates $^{3}$, M. Yel ${ }^{1}$, E. Olcay ${ }^{3}$ and S. Candan ${ }^{2}$

\author{
${ }^{1}$ Department of Biology, Faculty of Education, and 'Department of Biology, \\ Faculty of Arts and Science, Gazi University, Ankara, Turkey \\ ${ }^{3}$ Department of Pharmacology, Refik Saydam Institute, Ankara, Turkey
}

\author{
Correspondence \\ Y. Kalender \\ Department of Biology \\ Faculty of Arts and Science \\ Gazi University \\ 06500, Teknikokullar, Ankara \\ Turkey \\ Fax: +90-312-212-2279 \\ E-mail: \\ kalender@quark.fef.gazi.edu.tr
}

Received November 26, 2001

Accepted August 20, 2002

\begin{abstract}
Idarubicin is an anthracycline antibiotic extensively used in acute leukemia. In the present study we investigated whether vitamin $\mathrm{E}$ and catechin can reduce the toxic effects of idarubicin. Vitamin E (200 IU $\mathrm{kg}^{-1}$ week $\left.{ }^{-1}\right)$, catechin $\left(200 \mathrm{mg} \mathrm{kg}^{-1}\right.$ week $\left.^{-1}\right)$, idarubicin $\left(5 \mathrm{mg} \mathrm{kg}^{-1}\right.$ week $\left.{ }^{-1}\right)$, idarubicin + vitamin E (200 IU kg-1 ${ }^{-1}$ week $\left.^{-1}\right)$, and idarubicin + catechin $\left(200 \mathrm{mg} \mathrm{kg}^{-1}\right.$ week $\left.{ }^{-1}\right)$ combinations were given to male Sprague-Dawley rats weighing 210 to $230 \mathrm{~g}$ ( $\mathrm{N}=6$ /group). Idarubicintreated animals exhibited a decrease in body and heart weight, a decrease in myocardial contractility, and changes in ECG parameters $(\mathrm{P}<0.01)$. Catechin + idarubicin- and vitamin $\mathrm{E}+$ idarubicin-treated groups exhibited similar alterations, but changes were attenuated in comparison to those in cardiac muscle of idarubicin-treated rats $(\mathrm{P}<0.05)$. Superoxide dismutase and catalase activity was reduced in the idarubicin-treated group $(\mathrm{P}<0.05)$. Glutathione peroxidase levels were decreased in the idarubicin-treated group $(\mathrm{P}<0.05)$ and reached maximum concentrations in the catechin- and catechin + idarubicintreated groups compared to control $(\mathrm{P}<0.01)$. Malondialdehyde activity was decreased in the catechin + idarubicin-treated groups compared to control and increased in the other groups, reaching maximum concentrations in the vitamin E-treated group $(\mathrm{P}<0.01)$. In electron microscopy studies, swelling of the mitochondria and dilatation of the sarcoplasmic reticulum of myocytes were observed in the idarubicintreated groups. In groups that were given idarubicin + vitamin E and idarubicin + catechin, the only morphological change was a weak dilatation of the sarcoplasmic reticulum. We conclude that catechin and vitamin E significantly reduce idarubicin-induced cardiotoxicity in rats.
\end{abstract}

\section{Introduction}

Anthracyclines are important drugs for the treatment of lymphoma. Idarubicin is currently the most important anthracycline used orally and intravenously in clinical practice. Idarubicin is active in acute leukemia
Key words - Idarubicin

- Catechin

- Vitamin E

- Cardiotoxicity

- Ultrastructure and various solid tumors (1-3). In preclinical studies, idarubicin has demonstrated several potential advantages over daunorubicin and adriamycin, including reduced cardiotoxicity (4), a dose-limiting factor in anthracycline therapy. Several approaches have been developed in an effort to minimize this ef- 
fect. Different treatment schedules were used to decrease drug levels in plasma and myocardium and it has also been proposed that free radical scavengers and flavonoids might be effective in reducing the pathological changes observed after anthracycline treatment (5-8). Others have suggested that anthracycline-induced cardiotoxicity is not related to changes in free radical metabolism $(9,10)$. Using spin trapping techniques, Mimnaugh et al. (11) observed increased production of superoxide, $\mathrm{OH}^{-}$, conjugated dianes, malonaldehyde as well as changes in the enzymatic activity of peroxidase and catalase (CAT) in several biological systems following anthracycline therapy. Catechin is a member of the flavonoid family, which has a variety of pharmacological effects such as cardioprotective, diuretic and hypotensive actions (12). Antioxidants have also been shown to have protective functions and to play an important role in hydroxyl radicalcaused defects $(13,14)$. Hydrogen peroxide generated by mitochondria is primarily derived from the superoxide radical. These radical species may generate hydroxyl radicals by the Haber-Weiss reaction. Malonylaldehyde, the end product of lipid peroxidation, has also been measured to indicate the presence of free radicals and lipid peroxidation-induced cardiotoxicity. Suppression of superoxide dismutase (SOD) and CAT activities resulted in the reduction of oxygenized glutathione in cardiac tissues $(11,15)$. Some authors have found that vitamin E can reverse suppression of enzyme activities and the glutathione cascade (16).

The aim of the present study was to determine whether catechin and vitamin E prevent idarubicin-induced free radical formation and display cardioprotective effects.

\section{Material and Methods}

\section{Animals}

Male Sprague-Dawley rats (weighing approximately 210-230 g) obtained from the Refik Saydam Central Hygiene Institute, Ankara, Turkey, were used. The animals were housed in plastic cages, fed a normal laboratory diet and water ad libitum, and treated in accordance with the guidelines of the Animal Care Committee of the Hifzissihha Institute, Ministry of Health, Turkey. Animals were quarantined for 10 days before being randomized into experimental groups of six animals per cage.

\section{Drugs}

Idarubicin was supplied by Carlo Erba (Milano, Italy), catechin by Sigma (Ronkonkoma, NY, USA) and vitamin E by Roche (Basel, Switzerland). The drugs were reconstituted in sterile water prior to use. The concentration of catechin was adjusted to contain the required dose in $1 \mathrm{ml}$ and injected intraperitoneally $(i p)$ in each experiment.

\section{Animal studies and treatment schedules}

All rats were treated for 6 weeks. Control group: $1 \mathrm{ml}$ sterile water was administered intravenously (iv) every week. Idarubicin toxicity: idarubicin (5 mg kg-1 week $\left.^{-1}\right)$ was administered $i v$. Catechin control: catechin (200 mg kg-1 week $^{-1}$ ) was dissolved in distilled water and administered ip. Vitamin $E$ control: vitamin E (200 IU kg-1 week $\left.^{-1}\right)$ was administered $i v$. Effect of catechin on myocardial toxicity of idarubicin: catechin (200 mg kg-1 week $^{-1}$ ) was administered ip 30 min after $i v$ administration of idarubicin $(5 \mathrm{mg}$ $\mathrm{kg}^{-1}$ week $\left.^{-1}\right)$. Effect of vitamin E on myocardial toxicity of idarubicin: vitamin E (200 IU $\mathrm{kg}^{-1}$ week $^{-1}$ ) was administered iv 5 min after iv administration of idarubicin $\left(5 \mathrm{mg} \mathrm{kg}^{-1}\right.$ week $^{-1}$ ).

\section{Evaluation of general toxicity}

The body weight of the animals was re- 
corded weekly for 8 weeks as an index of general toxicity.

\section{Evaluation of cardiotoxicity}

The development of myocardial toxicity was monitored in vivo by electrocardiography (ECG) and subsequently evaluated by measuring the contractile performance of isolated atria and by electron microscopic examination of left ventricular samples excised 8 weeks after the beginning of the experiment. The remaining heart tissues were also prepared for enzymatic assays.

\section{Atrial contractility}

Myocardial contractility was evaluated in spontaneously beating atria isolated from animals at the end of 8 weeks and incubated in Tyrode solution aerated with a $95 \% \mathrm{O}_{2}+$ $5 \% \mathrm{CO}_{2}$ mixture at $37^{\circ} \mathrm{C}$. The contractile performance of isolated atria was assessed by subjecting the preparations to stepwise increases in resting tension and recorded by means of an isometric tension recording system: $\mathrm{dF} / \mathrm{dt}(\mathrm{g} / \mathrm{s})$ was used as the contractility index.

\section{ECG parameters}

ECGs were recorded at the beginning of treatment and subsequently at 2-week intervals. QT duration was measured for each tracing since the parameter was found to be related to the morphologic lesions developed by idarubicin-treated animals. QT was calculated as the interval between the Q wave and the apex of the $T$ wave (Grass polygraph model 7P, Grass Instruments Co., Quincy, MA, USA).

\section{Biochemical evaluation}

The right atrium and ventricles were removed and kept on ice until homogenization on the same day. The samples were first washed with deionized water to separate blood and then homogenized (Braun homogenizer) at $1,000 \mathrm{U}$ for about $3 \mathrm{~min}$. After centrifugation at $10,000 \mathrm{~g}$ for $60 \mathrm{~min}$, the upper layer was removed for determination of the amount of protein (17) and glutathione peroxidase (GSHPx) activity (18). A part of the homogenate was extracted with ethanol/ chloroform to eliminate lipids, which would have interfered with the measurements of SOD and CAT activity. GSHPx and CAT activities are reported as IU/mg protein. One unit of SOD is the amount of protein causing $50 \%$ inhibition in $\mathrm{NBTH}_{2}$ (a nitroblue tetrazolium salt) reduction rate. All enzyme activities are reported as specific activity (IU/ mg protein). The level of tissue malondialdehyde (MDA) was measured as described by Van Ye et al. (19). MDA levels are reported as $\mathrm{mmol} / \mathrm{g}$ tissue. All experiments were carried out at $4^{\circ} \mathrm{C}$.

\section{Electron microscopy}

Tissues were fixed in 3\% glutaraldehyde in $200 \mathrm{mM}$ sodium phosphate buffer, $\mathrm{pH}$ 7.4, for $3 \mathrm{~h}$ at $4^{\circ} \mathrm{C}$ for electron microscopic examination. Materials were washed with the same buffer and postfixed in $1 \%$ osmium tetroxide and in sodium phosphate buffer, $\mathrm{pH} 7.4$, for $1 \mathrm{~h}$ at $4^{\circ} \mathrm{C}$. Tissue samples were washed with the same buffer for $3 \mathrm{~h}$ at $4^{\circ} \mathrm{C}$, dehydrated in a graded ethanol series and embedded in Araldite. Thin sections were cut with a Reichert OM U3 ultramicrotome. Samples were stained with $2 \%$ uranyl acetate and lead citrate. The sections were viewed and photographed under a Jeol 100 CX II transmission electron microscope at $80 \mathrm{kV}$.

Statistical analysis was carried out using the Mann-Whitney U-test.

\section{Results}

\section{Evaluation of general toxicity}

No death was observed in any of the 
experimental groups. In the idarubicin-treated group, heart and body weights were significantly decreased compared to control $(\mathrm{P}<0.01)$. No significant differences were observed between vitamin E- and catechintreated groups and the control group $(\mathrm{P}>0.05)$. A decrease in body and heart weight was also observed in the catechin + idarubicinand vitamin $\mathrm{E}+$ idarubicin-treated groups compared to control $(\mathrm{P}<0.05)$. However, body and heart weight loss in the idarubicin group was more pronounced than that in the catechin + idarubicin and vitamin $\mathrm{E}+$ idarubicin groups (Table 1). An increase in body and heart weight was observed in catechin + idarubicin- and vitamin E + idarubicin-treated groups compared to the idarubicin-treated group $(\mathrm{P}<0.05$; Table 1$)$.

\section{Evaluation of cardiotoxicity}

Evaluation of atrial contractility. Atrial contractility of heart tissue was significantly decreased in the idarubicin-treated group compared to control $(\mathrm{P}<0.01)$, whereas no significant difference was observed between the vitamin E- and catechin-treated and the control group $(\mathrm{P}>0.05)$. The catechin + idarubicin- and vitamin E + idarubicin-treated groups also exhibited a decrease in atrial contractility $(\mathrm{P}<0.05)$, which, however, was less marked compared to the idarubicintreated group (Table 1). An increase was also seen in the vitamin $\mathrm{E}+$ idarubicintreated group compared to the idarubicintreated group $(\mathrm{P}<0.05)$, but not compared to the catechin + idarubicin-treated group ( $\mathrm{P}>0.05$; Table 1).

ECG alterations. QT duration significantly increased in idarubicin-treated animals particularly from the fourth week onwards compared to the control group $(\mathrm{P}<0.01$; Table 1). QT duration did not increase in the catechin- or vitamin E-treated groups compared to control $(\mathrm{P}>0.05$; Table 1$)$. In the catechin + idarubicin- and vitamin $\mathrm{E}+$ idarubicin-treated groups, QT duration was increased compared to control $(\mathrm{P}<0.05$; Table 2 ), with a more marked increase in the idarubicin-treated group than in the catechin + idarubicin- and vitamin E + idarubicintreated groups. Among the experimental groups, atrial contractility loss was maximum in the idarubicin-treated group (Table 1). In the catechin + idarubicin- and vitamin $\mathrm{E}+$ idarubicin-treated groups, atrial contractility was reduced compared to the idarubicintreated group $(\mathrm{P}<0.05$; Table 1$)$.

Biochemical results. The course of the enzymatic activities is presented in Table 2 (mean $\pm \mathrm{SD}$ ). There were differences in the enzyme activities among the different treat-

Table 1. Effect of idarubicin, vitamin E and catechin on body weight, heart weight, atrial contractility and QT interval.

\begin{tabular}{|c|c|c|c|c|}
\hline Group & Body weight (g) & Heart weight (g) & Atrial contractility (dF/dt) & QT interval (ms) \\
\hline Control & $220 \pm 7.0$ & $1.25 \pm 0.10$ & $19.00 \pm 2.40$ & $26.00 \pm 1.05$ \\
\hline Vitamin E (200 IU/kg) & $218 \pm 3.2$ & $1.24 \pm 0.12$ & $18.10 \pm 1.10$ & $26.00 \pm 1.10$ \\
\hline Catechin $(200$ mg/kg) & $211 \pm 3.1$ & $1.23 \pm 0.14$ & $16.21 \pm 2.10$ & $28.07 \pm 1.10$ \\
\hline Idarubicin $(5 \mathrm{mg} / \mathrm{kg})$ & $190 \pm 2.2^{*}$ & $1.02 \pm 0.10^{*}$ & $11.40 \pm 1.10^{*}$ & $39.30 \pm 1.70^{*}$ \\
\hline $\begin{array}{l}\text { Catechin }(200 \mathrm{mg} / \mathrm{kg}) \\
+ \text { idarubicin }(5 \mathrm{mg} / \mathrm{kg})\end{array}$ & $205 \pm 5.4^{*+}$ & $1.19 \pm 0.14^{*+}$ & $13.00 \pm 0.50^{*}$ & $33.11 \pm 0.50^{*+}$ \\
\hline $\begin{array}{l}\text { Vitamin E (200 IU/kg) } \\
+ \text { idarubicin }(5 \mathrm{mg} / \mathrm{kg})\end{array}$ & $210 \pm 4.0^{*+}$ & $1.21 \pm 0.15^{*+}$ & $15.30 \pm 1.10^{*+}$ & $31.40 \pm 0.10^{*+}$ \\
\hline
\end{tabular}


ment groups. SOD activity was decreased in the idarubicin-treated group compared to control $(\mathrm{P}<0.05$; Table 2$)$ and significantly increased in the catechin-treated group but not in the vitamin E-treated group $(\mathrm{P}<0.01$; Table 2). The catechin + idarubicin- and vitamin $\mathrm{E}+$ idarubicin-treated groups showed no difference compared to control $(\mathrm{P}>0.05)$. SOD activity in the catechin + idarubicinand vitamin $\mathrm{E}+$ idarubicin-treated groups did not differ from control $(\mathrm{P}>0.05$; Table 2).

A significant decrease in GSHPx activity was observed in the idarubicin-treated group compared to control $(\mathrm{P}<0.05)$. GSHPx activity was increased in the catechin-treated group compared to control, but no difference was observed in the vitamin E-treated group. GSHPx activity was significantly increased in the catechin + idarubicin-treated group compared to control, whereas no difference was observed in the vitamin $\mathrm{E}+$ idarubicintreated group. The maximum increase in GSHPx activity was observed in the catechin- and catechin + idarubicin-treated groups $(\mathrm{P}<0.01)$.

A significant increase in GSHPx activity was observed in the catechin + idarubicintreated group compared to the idarubicintreated $(\mathrm{P}<0.01)$ and the vitamin $\mathrm{E}+$ idarubicin-treated groups $(\mathrm{P}<0.05$; Table 2$)$.
CAT activity was significantly increased in the idarubicin-treated and catechin-treated groups compared to control $(\mathrm{P}<0.05)$ but no change was observed in the vitamin E-treated group (Table 2). No differences were observed in the catechin + idarubicin- and vitamin $\mathrm{E}+$ idarubicin-treated groups compared to control $(\mathrm{P}>0.05)$. The increase in CAT activity was maximum in the catechin-treated group $(\mathrm{P}<0.01)$. CAT activity was increased in the catechin + idarubicin- and vitamin $\mathrm{E}+$ idarubicin-treated groups compared to the idarubicin-treated group $(\mathrm{P}<0.05$; Table 2$)$.

MDA activity was significantly increased in the vitamin E-, catechin-, idarubicin- and vitamin $\mathrm{E}+$ idarubicin-treated groups, with the maximum increase being observed in the vitamin E-treated group $(\mathrm{P}<0.01$; Table 2$)$. MDA activity was decreased in the catechin + idarubicin-treated group compared to control $(\mathrm{P}<0.05)$ and in the catechin + idarubicintreated group compared to the idarubicintreated group $(\mathrm{P}<0.05)$. In the vitamin $\mathrm{E}+$ idarubicin-treated group there was an increase compared to the idarubicin-treated group ( $\mathrm{P}<0.05$; Table 2).

Electron microscopy. No significant differences in cardiac muscle cell preparations were observed between the catechin, vitamin $\mathrm{E}$ and control groups (Figure 1A). The electron micrographs of heart muscles of

Table 2. Effect of drug treatment on some enzyme activities in rat heart muscle.

\begin{tabular}{lcccc}
\hline Group & SOD (IU/mg) & GSHPx (IU/mg) & CAT (IU/mg) & MDA (mmol/g) \\
\hline Control (saline) & $20.45 \pm 3.76$ & $94.86 \pm 18.11$ & $25.99 \pm 11.44$ & $0.233 \pm 0.011$ \\
Vitamin E (200 IU/kg) & $21.51 \pm 5.14$ & $100.60 \pm 1.14$ & $30.14 \pm 14.16$ & $0.312 \pm 0.09^{*}$ \\
Catechin $(200 \mathrm{mg} / \mathrm{kg})$ & $30.40 \pm 5.80^{*}$ & $130.61 \pm 26.20^{*}$ & $64.38 \pm 22.46^{*}$ & $0.240 \pm 0.04^{*}$ \\
$\quad$ Idarubicin $(5 \mathrm{mg} / \mathrm{kg})$ & $13.16 \pm 1.04^{*}$ & $70.13 \pm 11.17^{*}$ & $16.01 \pm 1.10^{*}$ & $0.243 \pm 0.21^{*}$ \\
$\quad \begin{array}{l}\text { Catechin }(200 \mathrm{mg} / \mathrm{kg}) \\
\quad+\text { idarubicin }(5 \mathrm{mg} / \mathrm{kg})\end{array}$ & $16.13 \pm 2.14$ & $124.70 \pm 21.14^{*+}$ & $24.71 \pm 7.04^{+}$ & $0.219 \pm 0.09^{*+}$ \\
$\quad$ & & & & \\
$\quad \begin{array}{l}\text { Vitamin E }(200 \mathrm{lU} / \mathrm{kg}) \\
+ \text { idarubicin }(5 \mathrm{mg} / \mathrm{kg})\end{array}$ & $16.05 \pm 2.12$ & $91.21 \pm 1.14^{+}$ & $23.13 \pm 2.13^{+}$ & $0.262 \pm 0.19^{*+}$ \\
& & & &
\end{tabular}

Data are reported as means \pm SD. $N=6$ animals for all experiments.

${ }^{*} \mathrm{P}<0.05$ compared to control group;

$+P<0.05$ catechin + idarubicin- or vitamin $E+$ idarubicin-treated groups compared to idarubicin-treated group (Mann-Whitney test).

$\mathrm{SOD}=$ superoxide dismutase, $\mathrm{GSHPx}=$ glutathione peroxidase, $\mathrm{CAT}=$ catalase, $\mathrm{MDA}=$ malondialdehyde . 
idarubicin-treated rats showed mitochondrial vacuolization and swelling (Figure 1B), as well as dilatation of the sarcoplasmic reticulum (Figure 1C). As shown in Figure 2A and $\mathrm{B}$, no pathological findings were observed in the idarubicin + vitamin E- and idarubicin + catechin-treated groups, although these groups showed a significant sarcoplasmic reticulum dilatation in myocardial cells.

\section{Discussion}

The administration of $5 \mathrm{mg} / \mathrm{kg}$ idarubicin per week to rats for 6 weeks induced signs of

Figure 1. Effect of idarubicin on heart muscle ultrastructure. A, Control rat showing normal myocyte structure. Arrows show sarcoplasmic reticulum. B, Idarubicin-treated rat showing swelling and vacuolization of mitochondria. C, Idarubicin-treated rat showing dilatation of the sarcoplasmic reticulum (asterisks). $\mathrm{M}$ Mitochondria. N, nucleus; L, lipid body. $A=10,000 X, B=$ $10,000 X, C=12,000 X$
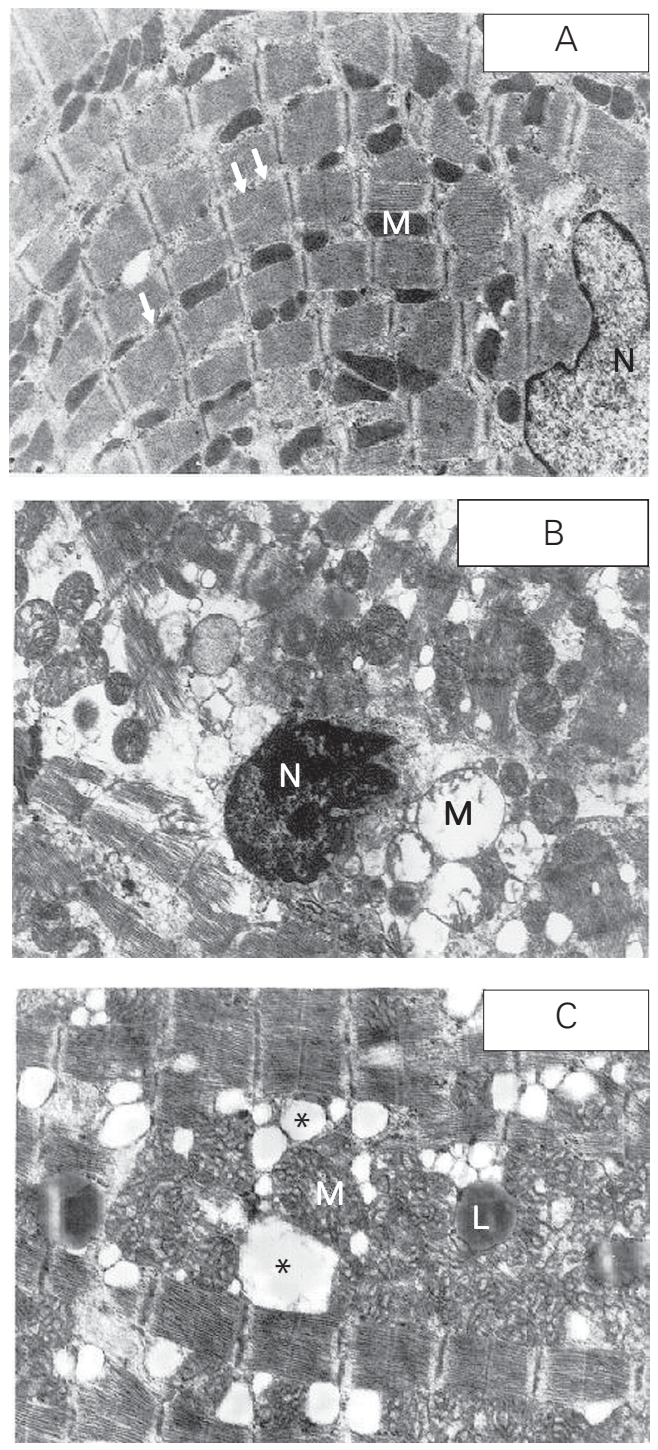

general toxicity as demonstrated by a significant reduction of body weight gain and delayed manifestations of cardiac toxicity including irreversible prolongation of QT intervals, impairment of contractility of isolated myocardial preparations, and a typical pattern of morphologic alterations similar to that observed in patients treated with anthracyclines (20-24). Idarubicin has less toxic effects than doxorubicin and daunorubicin (25-27). In this study, idarubicin caused a decrease in body and heart weight. It is known that antibiotics such as doxorubicin, daunorubicin and idarubicin cause weight loss (28-30). For this reason, prolonged use and excessive doses of these agents cause death. These drugs cause disruption of basal metabolism due to their toxic effect especially on liver and heart tissues.

Free radical formation has been proposed as a major mechanism of idarubicin cardiotoxicity. However, it is now believed that there are two mechanisms by which quinone drugs can generate reactive free radicals $(15,31)$. One involves a one electron reduction of the drug to a semiquinone free radical intermediate followed by a cascade of reactive oxygen species resulting from reaction with molecular oxygen. The second mechanism of free radical formation depends on the interaction of doxorubicin with metal ions, especially iron (31-33). In cardiac cells, a one electron reduction of anthracycline catalyzed by NADPH-cytochrome c-reductase forms the semiquinone radical, which in the presence of molecular oxygen leads to superoxide formation. These species are then converted by SOD into $\mathrm{H}_{2} \mathrm{O}_{2}$ and $\mathrm{O}_{2}$. In the presence of $\mathrm{Fe}^{2+}, \mathrm{H}_{2} \mathrm{O}_{2}$ is reduced to $\mathrm{OH}^{*}$ (Fenton reaction). These radicals have been shown to be key mediators of myocardial reperfusion injury and lipid peroxidation $(33,34)$. Evidence for oxygen free radical formation is an increased drug action when cellular levels of glutathione, GSHPx, SOD, CAT or other protective agents against free radical are low $(35,36)$. In addition, the toxic 
effects may be prevented by supplementation with protective vitamin $\mathrm{E}$ or enzymes $(5,28,37)$. Superoxides or their decomposition products, $\mathrm{H}_{2} \mathrm{O}_{2}$ and $\mathrm{OH}^{*}$, initiate lipid peroxidation by abstracting hydrogen atoms from unsaturated fatty acids (11). The detection of MDA supports this view. Moreover, treatment with idarubicin depletes cardiac cells of selenium-dependent GSHPx, an enzyme responsible for detoxifying oxygenderived toxic species. Thus, idarubicin not only increases free radical production in the heart, but also decreases its ability to detoxify reactive oxygen species. Possible reasons for the lowered SOD and GSHPx activities of heart tissues might be inhibition of enzyme protein synthesis, inhibition of enzymes by idarubicin, metabolites or some lipid peroxidation products. We believe that the changes observed in the antioxidant defense capacity might play a role in idarubicininduced cardiotoxicity. Increased MDA radical levels as well as electron microscopic examination of the affected heart tissues support this view.

Time and dose schedules of catechin administration were chosen so that high levels of scavenging activities were reached during early stages of the presence of anthracycline in the myocardium. Additionally, we performed in vitro experiments using an ironloaded rat heart impairment model which renders the heart atonous in order to select the appropriate dose of catechin because high and long-term catechin therapy had toxic effects on cardiac cells. Catechin was chosen for the present investigation because of its iron-chelating and antioxidant properties. It seems that not only the ability to dispose efficiently of oxygen metabolites but also the capacity to remove iron play an important role in protecting tissues against idarubicin toxicity. Previous observations showed that the antioxidant power of catechin was related to its free radical scavenging activity $(14,29)$. Also, in the present study catechin inhibited heart weight loss,
QT interval prolongation and the decrease in atrial beating induced by idarubicin treatment. Idarubicin affects cells and thus produces free oxygen radicals and causes cardiotoxicity. Radicals might activate the quamine redox reaction by using superoxide anion, causing dismutation that results in a decrease in hydrogen peroxide, CAT, and GSHPx. Catechin caused an increase in the levels of these enzymes and catechin and idarubicin also caused a slight increase in these enzymes.

In many studies vitamin $\mathrm{E}$ was shown to neutralize lipid peroxidation and unsaturated membrane lipids because of its oxygen scavenging effect (7). However, some investigators have stated that these effects of vitamin $\mathrm{E}$ are observed at doses of $200 \mathrm{mg} \mathrm{kg}^{-1}$ day $^{-1}(30)$. Vitamin E protects cells and subcellular structures from oxidative damage by inhibiting oxygen formation, and by decreasing MDA levels. There were no toxic effects of vitamin $E$ at the doses utilized here. Vitamin $\mathrm{E}$ increased MDA levels while decreasing SOD, GSHPx and CAT levels or keeping

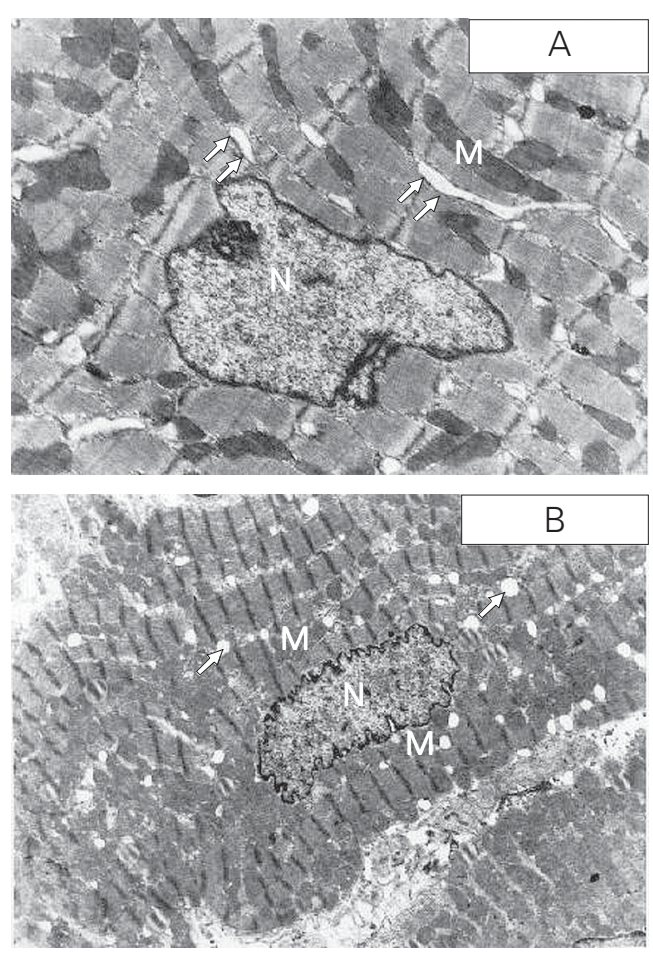

Figure 2. Effect of vitamin $E$ and catechin treatment on idarubicin-induced changes in rat heart ultrastructures. A, Vitamin $\mathrm{E}+$ idarubicin-treated rats. $B$, Catechin + idarubicin-treated rats. Mitochondria (M); sarcoplasmic reticulum (arrow); nucleus (N). A $=10,000 \mathrm{X}, \mathrm{B}=6,500 \mathrm{X}$. 
their original concentrations. This suggests that vitamin E used single oxygen formation pathway. Vitamin E alone or in combination with idarubicin treatment might also inhibit the general toxic and cardiotoxic effects of idarubicin.

Electron microscopic studies showed that idarubicin damages myocardial cells. This effect was seen in the mitochondria and sarcoplasmic reticulum of myocardial cells. However, catechin + idarubicin- and vitamin $\mathrm{E}+$ idarubicin-treated groups showed no changes in the morphology of myocardial cells. Taken together, the present pharmacodynamic, biochemical and electron microscopy studies indicate that the idarubicininduced cardiotoxic effect can be significantly reduced by catechin and vitamin $\mathrm{E}$.

\section{Acknowledgments}

We gratefully acknowledge Professor Ilker Durak, Department of Biochemistry, Medical School of Ankara University, for his support.

\section{References}

1. Carella $A M$, Santini $G$ \& Martinengo $M$ (1985). 4-Demethoxydaunorubicin (idarubicin) in refractory or relapsed acute leukemias: a pilot study. Cancer, 55: 14521454.

2. Daghestani AN \& Leyland-Jones B (1985). Phase I and II clinical and pharmacological study of 4-demethoxydaunorubicin (idarubicin) in adult patients with acute leukemia. Cancer Research, 45: 1408-1412.

3. Ganzina F, Pacciarini MA \& Di Pietro N (1986). Idarubicin (4-demethoxydaunorubicin): a preliminary overview of clinical and preclinical studies. Investigational New Drugs, 4: 85-105.

4. Casazza AM (1979). Experimental evaluation of anthracycline analogs. Cancer Treatment Reports, 63: 835-844.

5. Myers CE, McGuire WP, Liss RH, Ifrim I, Grotzinger K \& Young RC (1977). Adriamycin: the role of lipid peroxidation in cardiac toxicity and tumor response. Science, 197: 165-167.

6. Sonneveld P (1978). Effect of $\alpha$-tocopherol on the cardiotoxicity of adriamycin in the rat. Cancer Treatment Reports, 62: 1033-1036.

7. Wang YM, Madanat FF, Kimball JC, Gleiser CA, Ali MK, Kaufman MW \& van Eys J (1980). Effect of vitamin E against adriamycin-induced toxicity in rabbits. Cancer Research, 40: 1022-1027.

8. Milei J, Boveris A, Llesuy S, Molina HA, Storino R, Ortega D \& Milei SE (1986). Amelioration of adriamycin-induced cardiotoxicity in rabbits by prenylamine and vitamins $A$ and E. American Heart Journal, 111: 95-102.

9. Herman EH \& Ferrans VJ (1987). Amelioration of chronic anthracyclines cardiotoxicity by ICRF-187 and other compounds.
Cancer Treatment Reviews, 14: 225-229.

10. Alderton P, Gross J \& Green MD (1990). Role of (+)-1,2-bis (3,5-dioxopiperazinyl-1yl) propana (ICRF-187) in modulating free radical scavenging enzymes in doxorubicin-induced cardiomyopathy. Cancer Research, 50: 5136-5142.

11. Mimnaugh EG, Kenedy KA, Trush MT \& Sinha BK (1985). Adriamycin enhanced membrane lipid peroxidation in isolated rat nuclei. Cancer Research, 45: 32963304

12. Bors W, Heller W, Michel C \& Saran M (1990). Flavonoids as antioxidants: determination of radical-scavenging efficiencies. Methods in Enzymology, 186: 343355.

13. Wang C (1981). Pharmacokinetics in Pharmacology. Lippincott Academic Press, New York, NY, USA, 671-681.

14. Hodnick WF, Kung FS, Roettger WJ, Bohmont CW \& Pardini RS (1986). Inhibition of mitochondrial respiration and production of toxic oxygen radicals by flavonoids. Biochemical Pharmacology, 35: 2345-2357.

15. Mimnaugh EG, Gram TE \& Trush MA (1983). Stimulation of mouse heart and liver microsomal lipid peroxidation by anthracycline anticancer drugs: characterization and effects of reactive oxygen scavengers. Journal of Pharmacology and Experimental Therapeutics, 226: 806-816.

16. Milner LS, Wei SH, Stohs SJ, Eldeen ZM \& Houser MT (1992). Role of glutathione metabolism in the reduction of proteinuria by dimethylthiourea in adriamycin nephrosis. Nephron, 62: 192-197.

17. Lowry $\mathrm{OH}$, Rosebrough NJ, Farr $\mathrm{AL}$ \& Randall RJ (1951). Protein measurement with the Folin phenol reagent. Journal of
Biological Chemistry, 183: 265-275.

18. Paglia DE \& Valentine WN (1967). Studies on the quantitative and qualitative characterisation of erythrocyte glutathione peroxidase. Journal of Laboratory and Clinical Medicine, 70: 158-169.

19. Van Ye TM, Roza AM, Pieper GM, Henderson Jr J, Johnson CP \& Adams MB (1993). Inhibition of intestinal lipid peroxidation does not minimize morphological damage. Journal of Surgical Research, 55: 553-558.

20. Bristow MR, Minobe WA, Billingham ME, Marmor JB, Johnson GA, Ishimoto BM, Sageman S \& Daniels JR (1981). Anthracycline-associated cardiac and renal damage in rabbits. American Heart Journal, 45: 157-168.

21. Bristow MR, Mason JW, Billingham ME \& Daniels JR (1981). Dose-effect and structure-function relationships in doxorubicin cardiomyopathy. Laboratory Investigation, 102: 709-718.

22. Torti FM, Bristow MR, Howes AE, Aston D, Stockdale FE, Carter SK, Kohler M, Brown BW \& Billingham ME (1983). Reduced cardiotoxicity of doxorubicin delivered on a weekly schedule. Annals of Internal Medicine, 99: 745-749.

23. Villani F, Galimberti M \& Comazzi R (1991). Early cardiac toxicity of $4^{\prime}$-iodo4'-deoxydoxorubicin. European Journal of Cancer, 27: 1601-1604.

24. Wakasugi S, Fischman AJ, Babich JW, Callahan RJ, Elmaleh DR, Wilkinson R \& Strauss W (1993). Myocardial substrate utilization and left ventricular function in adriamycin cardiomyopathy. Journal of Nuclear Medicine, 34: 1529-1535.

25. Bertelli G, Amoroso D, Pronzato P \& Rosso R (1988). Idarubicin: An evaluation 
of cardiac toxicity in 77 patients with solid tumors. Anticancer Research, 8: 645-646.

26. Christoffersen PS, Rasmussen KK \& Hermansen K (1988). Cardiovascular effects of doxorubicin (adriamycin) and 4demethoxydaunorubicin (idarubicin) in the conscious rat. Pharmacology and Toxicology, 62: 54-56.

27. Villani F, Galimberti A, Comazzi R \& Crippa $F$ (1989). Evaluation of cardiac toxicity of idarubicin (4-demethoxydaunorubicin). European Journal of Cancer, 25: 13-18.

28. Kalender S, Kavutcu M, Kalender Y, Olcay E, Yel M \& Ates A (2001). Protective role of antioxidant vitamin $E$ and catechin on doxorubicin-induced cardiotoxicity in rats. Cancer Research, Therapy and Control, 11: 175-182.

29. Kozluca O, Olcay E, Sürücü S, Güran Z, Kulaksiz T \& Üskent N (1995). Prevention of doxorubicin induced cardiotoxicity by catechin. Cancer Letters, 98: 1-6.
30. Kavutcu M, Canbolat O, Öztürk S, Olcay E, Ulutepe S, Ekinci C, Gökhun IA \& Durak I (1996). Reduced enzymatic antioxidant defense mechanism in kidney tissues from gentamicin-treated guinea pigs: effect of vitamins E and C. Nephron, 72: 269-274.

31. Doroshow JS (1983). Anthracycline antibiotic-stimulated superoxide, hydrogen peroxide and hydroxyl radical production by NADH dehydrogenase. Cancer Research, 43: 4543-4551.

32. Myers $C E$, Gianni L, Simone $C B$, Kleker $R$ \& Green R (1982). Oxidative destruction of erythrocyte ghost membranes catalyzed by the doxorubicin-iron complexes. Biochemistry, 21: 1707-1713.

33. Rajagopalan S, Politi PM, Sinha K \& Myers CE (1988). Adriamycin-induced free radical formation in the perfused rat heart: Implications for cardiotoxicity. Cancer Research, 48: 4766-4769.
34. Thompson JA \& Hess ML (1986). The oxygen free radical system: A fundamental mechanism in the production of myocardial necrosis. Progress in Cardiovascular Diseases, 28: 449-462.

35. Bozzi A, Mavelli I, Mondovi R, Strom R \& Rotilio G (1981). Differential cytotoxicity of daunomycin in tumour cells is related to glutathione-dependent hydrogen peroxide metabolism. Biochemical Journal, 194: 369-372.

36. Grankvist K, Stendahl U \& Henrikson R (1989). Comparative study of demethoxydaunorubicin with other anthracyclines on generation of oxygen radicals and clonogenic survival of fibroblasts. Pharmacology and Toxicology, 65: 40-44.

37. Babson JR, Abell NS \& Reed DJ (1981). Protective role of the glutathione redox cycle against adriamycin-mediated toxicity in isolated hepatocytes. Biochemical Pharmacology, 30: 2299-2304. 